\title{
SYNOPSES
}

\section{FINANCIAL OPTIONS IN LIFE ASSURANCE POLICIES}

\author{
by \\ R. G. GILLESPIE \\ (Synopsis of a paper presented to the Society on 17 March 1981)
}

The purpose of the paper is to describe very broadly the various methods of dealing with options in life policies and, in particular, to contrast traditional methods of calculation with the new methods developed to deal with maturity guarantees on unit-linked contracts. The paper advocates use of methods of costing and of valuation based on risk theory.

Options are classified under a number of heads, broadly as either mortality options, rate guarantee options, or benefit guarantee options. A distinction is drawn between benefit guarantees on linked contracts and those on non-linked contracts and also between single and annual premium rate guarantees.

The statistical considerations underlying traditional methods of calculation of option premiums are discussed and the calculations are shown to rely on the assumption of independence.

The potential mismatching risk implicit in a guarantee of annual premium rates is identified, although the risk is not great for the usual form of such options.

The problem of reserving for maturity guarantees on unit-linked contracts is discussed, and the paper covers, from a different viewpoint, many of the questions addressed by the Institute Working Party on the subject of maturity guarantees.

The techniques developed by the Working Party are also appropriate for costing of single premium rate guarantees such as, for example, an annuity option on an endowment assurance or deferred annuity.

Continuing benefit guarantees are shown to involve even larger risks than point-in-time guarantees, because of the possible incentive to the policyholder to maximize the guarantee cost.

Lastly the risks implicit in guarantees of surrender values on 
non-linked contracts are discussed. Although such guarantees are usual in North America, and although a demand is known to exist in Britain, the potential damage from high and volatile interest rates is judged to be very significant.

The paper concludes in the view that in meeting market demand for flexible options the profession should use modern statistical methods to fully analyse all the risks involved.

\title{
THE FINANCIAL MANAGEMENT OF A DEVELOPING LIFE OFFICE
}

\author{
by \\ D. J. LE GRYS
}

(Synopsis of a paper presented to the Society on 4 November 1980)

The Financial Management of a Developing Life Office was produced in 1979 and was principally written for managers and directors of newly established Life Offices in the United Kingdom. Most of these offices write non profit and unit-linked types of life assurance business and this book concentrates on the problems related to these policies.

The aim was to produce an outline of the main factors affecting a life office as it developed, and to highlight constraints and dangers.

\section{Chapter 1}

The capital requirements for a developing life office are explained and the concept of a 'corridor for development' is defined. Although a new office may be attracting business at profitable terms, the office must keep its production below a maximum production limit otherwise it will exhaust the shareholders' capital. On the other hand the office must reach a certain minimum production limit if it is to trade successfully and to earn profits in the long term.

The five main factors that affect the development of a new life office are defined as the marketing terms, expense performance, investment and reserve requirements, tax position and inflation. 